\title{
Tapping the biotechnological potential of insect microbial symbionts: new insecticidal porphyrins
} (1) CrossMark

\author{
Ana Flávia Canovas Martinez ${ }^{1 *}$, Luís Gustavo de Almeida', Luiz Alberto Beraldo Moraes² \\ and Fernando Luís Cônsoli ${ }^{*}$
}

\begin{abstract}
Background: The demand for sustainable agricultural practices and the limited progress toward newer and safer chemicals for use in pest control maintain the impetus for research and identification of new natural molecules. Natural molecules are preferable to synthetic organic molecules because they are biodegradable, have low toxicity, are often selective and can be applied at low concentrations. Microbes are one source of natural insecticides, and microbial insect symbionts have attracted attention as a source of new bioactive molecules because these microbes are exposed to various selection pressures in their association with insects. Analytical techniques must be used to isolate and characterize new compounds, and sensitive analytical tools such as mass spectrometry and high-resolution chromatography are required to identify the least-abundant molecules.
\end{abstract}

Results: We used classical fermentation techniques combined with tandem mass spectrometry to prospect for insecticidal substances produced by the ant symbiont Streptomyces caniferus. Crude extracts from this bacterium showed low biological activity (less than 10\% mortality) against the larval stage of the fall armyworm Spodoptera frugiperda. Because of the complexity of the crude extract, we used fractionation-guided bioassays to investigate if the low toxicity was related to the relative abundance of the active molecule, leading to the isolation of porphyrins as active molecules. Porphyrins are a class of photoactive molecules with a broad range of bioactivity, including insecticidal. The active fraction, containing a mixture of porphyrins, induced up to $100 \%$ larval mortality $\left(\mathrm{LD}_{50}=37\right.$. $7 \mu \mathrm{g} . \mathrm{cm}^{-2}$ ). Tandem mass-spectrometry analyses provided structural information for two new porphyrin structures. Data on the availability of porphyrins in 67 other crude extracts of ant ectosymbionts were also obtained with ion-monitoring experiments.

Conclusions: Insect-associated bacterial symbionts are a rich source of bioactive compounds. Exploring microbial diversity through mass-spectrometry analyses is a useful approach for isolating and identifying new compounds. Our results showed high insecticidal activity of porphyrin compounds. Applications of different experiments in mass spectrometry allowed the characterization of two new porphyrins.

Keywords: Acromyrmex coronatus, Bacterial symbionts, Sustainable pest control, Symbiosis, Tandem mass spectrometry

\footnotetext{
* Correspondence: anamartinez@usp.br; fconsoli@usp.br

'Laboratório de Interações em Insetos, Departamento de Entomologia e

Acarologia, Escola Superior de Agricultura "Luiz de Queiroz", Universidade de

São Paulo, Av Pádua Dias 11, 13418-900, Piracicaba, SP, Brazil

Full list of author information is available at the end of the article
} 


\section{Background}

Despite the use of new chemistries of synthetic organic pesticides and new technologies such as genetically modified plants that express bacterial entomotoxins [1-3], the continued crop losses to insect pests necessitate the development of new tools to prevent reductions in yield and undesired effects on non-target organisms and the environment [4]. The need for integrative, sustainable management practices has led to the development of incentives and policies to support the use of integrated pest management [5], a strategy based on multiple control techniques, including the use of natural products.

The need for new compounds with insecticidal activity has increased, especially due to the evolution of insect resistance against the majority of existing insecticides and the necessity for target-specific and environmentally friendly molecules [6]. Microbes have proved to be a rich source of new bioactive molecules [7-10]. The diversity of microbes associated with insects and the selective pressures on microbes due to the range of insect habitats, have stimulated research on insect-associated microorganisms as an untapped resource for biotechnological exploitation [11-13]. Microbial symbiosis (sensu de Bary) [14] in leafcutting ants is well studied, including the diversity and mode of transmission of bacteria associated with the cuticle of these ants [15-17]. These ectosymbionts play a defensive role in this association by producing bioactive molecules to protect the mutualistic fungi that these ants cultivate as their food resource, from infections with parasitic fungi [18-21]. The mutualistic association of ants with bacteria has been under debate as some report Pseudonocardia being the mutualistic bacterium associated with the cuticle of leaf cutting ants [22, 23], while others believe the protective role of cuticle associated bacteria is provided by a diverse community [24-26]. Andersen et al. [27] provided data demonstrating Pseudonocardia as the prevalent bacterium growing on the laterocervical plates and pronotum of ants; but their study analysed different colonies belonging only to Acromyrmex echinator and a couple of other species from different genera. The prevalence of Pseudonocardia in the microbiota associated with the ant cuticle and their efficiency against parasitic fungi of the ant's fungus garden certainly contributes to their role as a mutualist of ants. However, other bacterial species from the cuticle of ants were demonstrated to be more efficient in controlling the growth of the parasitic fungus Escovopsis than Pseudonocardia associated with Acromyrmex subterraneus brunneus [16]. Streptomycesproduced candicidin was demonstrated to be a powerful antibiotic against Escovopsis while inactive to the ant fungus garden [28]. Both studies indicate other members of the community associated with the cuticle of ants provide the same protective function as Pseudonocardia, supporting the proposition that the defensive contribution of the cuticle-associated microbiota is provided by a diverse community. Moreover, the ant-associated microbiota was also reported effective against entomopathogenic fungi [29], showing that these symbionts are a rich source of bioactive molecules [30] to protect the ant mutualist fungi and the ants themselves. Such controversy on the diversity of bacteria growing on the cuticle of ants and on their role in the association with ants could be a result of the varying degree of co-evolution of ants and Pseudonocardia [22], although phylogenetic assessment by others did not indicate any topological correspondence between Pseudonocardia and their host ants [31].

The identification of metabolites, a key challenge in the search for new bioactive molecules, is based on analytical techniques for structural characterization, such as mass spectrometry (MS) and nuclear magnetic resonance (NMR). Increasing the sensitivity and stability of characterization techniques has made viable studies of complex biological samples by dereplication, allowing the development of databases of metabolites to assist with the identification process [32].

Porphyrins are widely used in photodynamic therapies [33]. After photoactivation, porphyrins transfer energy to oxygen molecules that have changed their energy state (triplet to singlet), increasing oxygen reactivity and leading to cell death [34, 35]. Biotechnological applications of porphyrins are diverse [36-38] and include their successful use as insecticides [38, 39]. Porphyrins are well known for their phototoxic activity [39-42]. Photoactivity is related to the production of very toxic and highly reactive oxygen species (ROS) in the presence of UV or visible radiation. ROS is a term used for molecules and reactive intermediates with highly positive redox potentials [43]. ROS are produced when a photoactive substance, a photosensitizer (PS), is activated by low doses of UV-visible light at an appropriate wavelength. ROS can be produced as free radicals (Type I) or as singlet oxygen $\mathrm{O}_{2}\left({ }_{1} \mathrm{D}_{\mathrm{g}}\right.$ ) (Type II). The four major ROS studied are superoxide $\left(\mathrm{O}_{2}^{-}\right)$, hydrogen peroxide $\left(\mathrm{H}_{2} \mathrm{O}_{2}\right)$, hydroxyl radical $(\cdot \mathrm{OH})$ and singlet oxygen. Singlet oxygen is formed when an electron is removed from $\pi 2 p$ orbitals of oxygen. The photoactivity observed for porphyrins is Type II [42]. Singlet oxygen is understood to play a major role in this effect, and photoactive molecules are increasingly being used in blood sterilization, cancer therapy, and insect and weed control [44].

The great advantage in the use of porphyrins compared to other photodynamic molecules is their light-absorbing capacity at all wavelengths in the UV-visible spectrum, which allows porphyrin excitation under exposure to natural light [37].

Here, we describe the successful exploration of bacteria-associated insect symbionts as sources of new bioactive molecules, and report the structures of new 
porphyrins with insecticidal properties against the polyphagous fall armyworm, Spodoptera frugiperda (J.E. Smith) (Lepidoptera, Noctuidae), based on tandem MS (neutral-loss experiment).

\section{Results}

We used a classical strategy of fermentation and isolation of bioactive compounds to prospect for molecules with insecticidal activity produced by ectosymbionts of the leaf-cutting ant Acromyrmex coronatus. Our preliminary screening identified an isolate (IIL-Ac-18dV) that was tentatively identified as Streptomyces caniferus because it shared $99.98 \%$ identity over 1350 bp of $16 \mathrm{~S}$ rRNA with the type strain (AB184640). This isolate produced a complex crude extract (Fig. 1) with low insecticidal activity (approximately 10\% mortality) against first instars of $S$. frugiperda.

Preliminary experiments by Collision-induced dissociation (CID) of the crude extract of this isolate led to the identification of three chemical classes of compounds in the regions at $m / z 540-650, m / z 730-780$ and $m / z 785-840$.

Our experience with isolation of bioactive compounds produced by microorganisms indicates that these compounds are present in low concentrations in most cases. Therefore, we believed that biological activity could not be detected due to the very low concentration of the active compound in initial screenings. To prove this supposition, bioactivity and isolation experiments were conducted with the crude extract, which showed only $10 \%$ mortality in the initial screening, and these experiments led to the isolation and identification of an active compound. The higher activity after fractionation and isolation confirmed the complexity of the original crude extract and indicated that the lack of observation of porphyrin signals in the mass spectrum of the original crude extract was likely due to ionization suppression.

Toxicity-driven fractionation of the crude extract from the isolate IIL-Ac-ASP18v allowed the isolation of a fraction that contained a mixture of three porphyrins.
Bioassays of this fraction against third instars of S. frugiperda indicated high insecticidal activity, with a $\mathrm{LD}_{50}$ of $37.7 \mu$ g.cm ${ }^{-2}(y=1.876-1.051 \times ; n=72 ; d f=3$; $\left.X^{2}=6.0723 ; P<0.05\right)$. Larvae exposed to the porphyrin fraction turned black, which could be related to the oxidative process in cells and tissues exposed to porphyrins.

The purified porphyrins coproporphyrin and zinc coproporphyrin III using the estimated $\mathrm{LD}_{50}$ concentration caused approximately $30 \%$ mortality in third instars of S. frugiperda.

\section{Isolation and characterization of porphyrins in the active fraction}

Porphyrin signals were observed at $m / z$ 655, 669 and 717. The CID of an ion at $m / z 655$ produced a fragmentation profile that allowed the characterization of coproporphyrin $I$, as corroborated by comparison with data in the literature $[45,46]$. The CID spectrum of $m / z 655$ produced a neutral loss of $74 \mathrm{Da}(\mathrm{m} / z 581)$, which corresponded to losses of propionic acid $\left(\mathrm{CH}_{3} \mathrm{CH}_{2} \mathrm{COOH}\right), \alpha-$ cleavage was observed in losses of 59 Da. Four consecutive losses of $59 \mathrm{Da}$ were observed at $\mathrm{m} / z$ 596, 537, 478 and 419. Losses of 59 Da revealed radical losses. Consecutive losses of 59 and $73 \mathrm{Da}$ were also observed at $m /$ $z 596[\mathrm{M}-59+\mathrm{H}]^{+}, m / z 523[\mathrm{M}-59-73+\mathrm{H}]^{+}, m / z 464$ $[\mathrm{M}-59-73-59+\mathrm{H}]^{+}$and $m / z 391[\mathrm{M}-59-73-59-73+\mathrm{H}]^{+}$. Base peak $\mathrm{m} / \mathrm{z} 537$ corresponds to a loss of $118 \mathrm{Da}$, which corresponded to one radical of propionic acid $\left(\cdot \mathrm{CH}_{2} \mathrm{CH}_{2} \mathrm{COOH}\right)$ and three methyl groups $\left(\mathrm{CH}_{3}\right)$, while a loss of $132 \mathrm{Da}(\mathrm{m} / z 523)$ corresponded to losses of four methyl groups and one propionic acid residue. All losses followed radical mechanisms. The CID spectrum at $m / z 655$ and the predicted structure of this molecule are illustrated in Fig. 2a. The theoretical value of $\log P$ obtained for coproporphyrin I was 5.22.

One loss of $60 \mathrm{Da}(\mathrm{m} / z$ 657) and three consecutive losses of $59 \mathrm{Da}(\mathrm{m} / z 598,539$ and 480) were observed for an ion at $m / z$ 717. The fragmentation profile of the porphyrin at $m / z 717$ differed in showing losses of $72 \mathrm{Da}$ for ions at $\mathrm{m} / z$

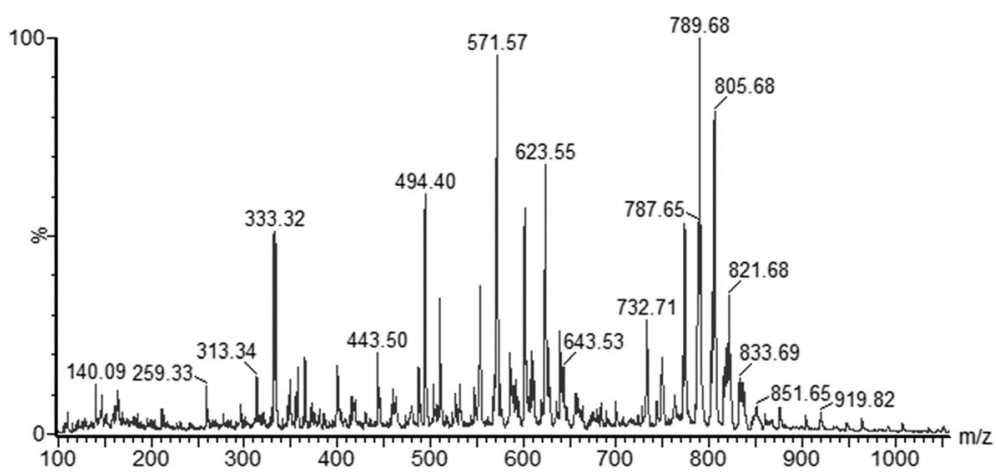

Fig. 1 Chemical profile obtained in positive mode (ESI+) by mass spectrometry of crude extract produced by Streptomyces caniferus 


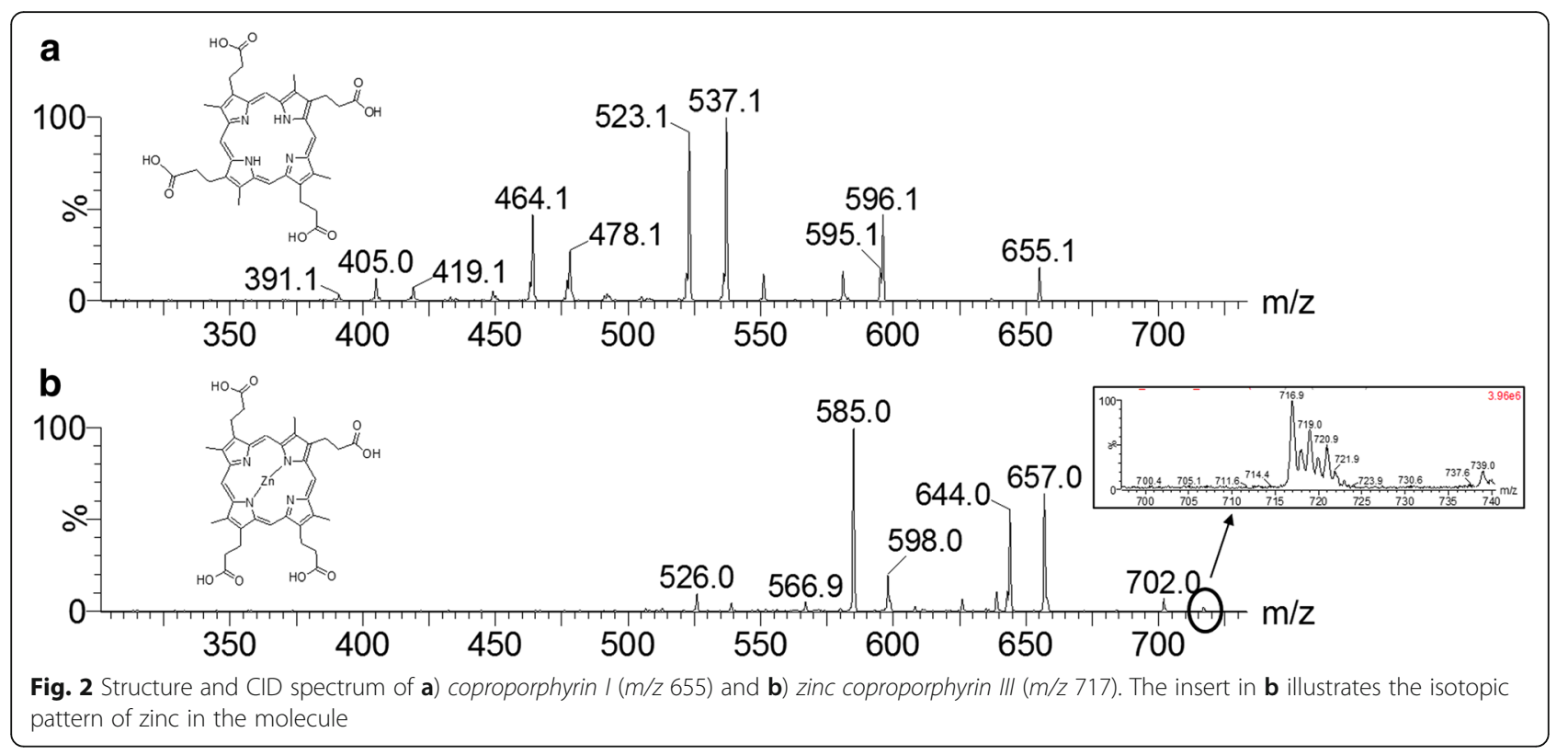

$585[\mathrm{M}-60-72+\mathrm{H}]^{+}$or $m / z 526[\mathrm{M}-60-59-72+\mathrm{H}]^{+}$or $m /$ $z 467[\mathrm{M}-60-59-59-72+\mathrm{H}]^{+}$. The ion at $\mathrm{m} / z 644$ corresponded to a loss of $73 \mathrm{Da}\left(\mathrm{CH}_{2} \mathrm{CH}_{2} \mathrm{COOH}\right)$. This structure corresponded to zinc coproporphyrin III. The CID spectra, isotopic profile and structure of zinc coproporphyrin III are illustrated in Fig. $2 \mathrm{~b}$.

Another porphyrin (porphyrin I) was available in the active fraction at $m / z 669$. The same fragmentation profile observed for an ion at $m / z 655$ was observed for this porphyrin. The fragmentation profile obtained for $\mathrm{m} / \mathrm{z}$ 669 by CID analysis produced four consecutive $\alpha$ cleavages, observed in radical losses of $59 \mathrm{Da}(\mathrm{m} / z 610$, 551,492 and 433) and neutral loss of $74 \mathrm{Da}(\mathrm{m} / z 595)$. Consecutive losses of 59 and 73 Da were also observed: $m / z 610[\mathrm{M}-59+\mathrm{H}]^{+}, m / z 537[\mathrm{M}-59-73+\mathrm{H}]^{+}, m / z$ $478[\mathrm{M}-59-73-59+\mathrm{H}]^{+}$and $m / z 405$ [M-59-73-59$73+\mathrm{H}]^{+}$. The signal at $m / z 523$ corresponded to loss of $146 \mathrm{Da}$, i.e. loss of one propionic acid residue, three methyl radicals $\left(\mathrm{CH}_{3}\right)$ and one ethyl radical $\left(\mathrm{CH}_{2} \mathrm{CH}_{3}\right)$. The theoretical $\log P$ value for hydrophobicity of porphyrin $I$ was 5.64 . The CID spectrum at $m / z 669$ and the predicted structure of this molecule are illustrated in Fig. 3a.

\section{Neutral-loss experiments}

Neutral-loss experiments for monitoring the availability of porphyrins in 67 crude extracts of insect microbial symbionts led to the identification of

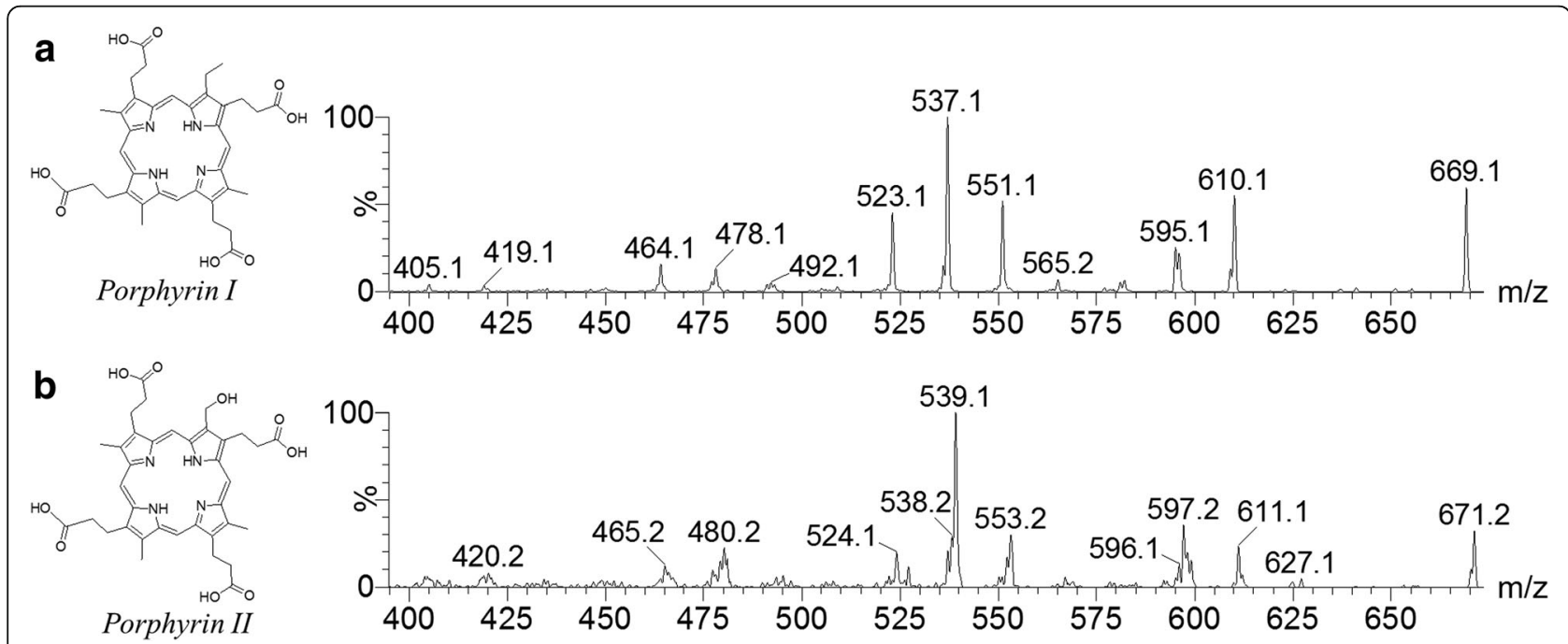

Fig. 3 Structures and CID spectra of new insect-associated microbial porphyrins. a) porphyrin / (m/z 669); b) porphyrin /I (m/z 671) 
porphyrins in the extracts produced by isolate IILAc-ASP40, putatively identified as Streptomyces olivochromogenes $(99 \%$ identity over a 1350-bp fragment of the 16S rRNA gene) and IIL-Ac-ASP72, putatively identified as Streptomyces eurocidicus (98.96\% identity over a 1350-bp fragment of the $16 \mathrm{~S}$ rRNA gene) (unpublished data). Porphyrins were identified by monitoring signals with $118 \mathrm{Da}$, $132 \mathrm{Da}, 74 \mathrm{Da}$ and $60 \mathrm{Da}$, all products of fragmentation of coproporphyrin I (Fig. 2a). Isolates IIL-AcASP40 and IIL-Ac-ASP72 produced two of the same porphyrins produced by isolate IIL-Ac-ASP18v, coproporphyrin $I$ at $m / z 655$ and the new porphyrin $I$ at $m / z 669$ (Fig. 3a). Neutral-loss experiments on the crude extract of isolate IIL-Ac-ASP18v resulted in the discovery of a new ion at $m / z 671$, allowing the identification of a fourth porphyrin (porphyrin II) (Figs. $3 \mathrm{~b}$ and 4 ).

The CID experiment resulted in an interesting fragmentation profile for ion $m / z$ 671. This structure showed the most distinct fragmentation profile, with neutral losses predominating over radical losses. $\alpha-$ cleavages were observed, with losses of 60 (neutral loss) or 59 (radical loss) Da. The signal at $\mathrm{m} / z 522$ corresponds to the loss of $148 \mathrm{Da}$, i.e. loss of one propionic acid residue, three methyl radicals $\left(\mathrm{CH}_{3}\right)$ and one methanol radical $\left(\mathrm{CH}_{2} \mathrm{OH}\right)$. The theoretical $\log P$ value for hydrophobicity of porphyrin II was 4.1. The CID spectrum at $m / z 671$ and the predicted structure of this molecule are illustrated in Fig. 3b.

\section{Discussion}

We demonstrated the potential of insect microbial symbionts to produce new molecules with insecticidal activity against the lepidopteran $S$. frugiperda, describing three new structures of photoactivated porphyrins. We also demonstrated that detailed structure analysis and molecule bioassay-guided isolation of active compounds from complex crude extracts with low biological activity can result in the isolation of new, highly active molecules: the new porphyrins $I$ and II. The porphyrins that were characterized in this study would not have been identified, nor would their insecticidal potential have been detected if we had followed a traditional approach, as the low proportion of porphyrins in the crude extract did not produce a promising insecticidal activity in the initial screening. Our results indicated that porphyrins can be used for insect control at low concentrations, as we demonstrated using third instars of Spodoptera frugiperda.

The insecticidal activity of the purified porphyrins coproporphyrin and zinc coproporphyrin III was lower than expected from the calculated $\mathrm{LD}_{50}$. This lower than expected mortality could be related to synergism among the different porphyrins in the whole fraction, and/or the additional manipulation for porphyrin purification having allowed some degradation. For example, the antineoplastic activity and in vitro photophysical properties of Photofrin photodynamic therapy, also based on a mixture of porphyrins, are uncertain, owing to the variable pharmacokinetics and photochemistry of the constituents [47].
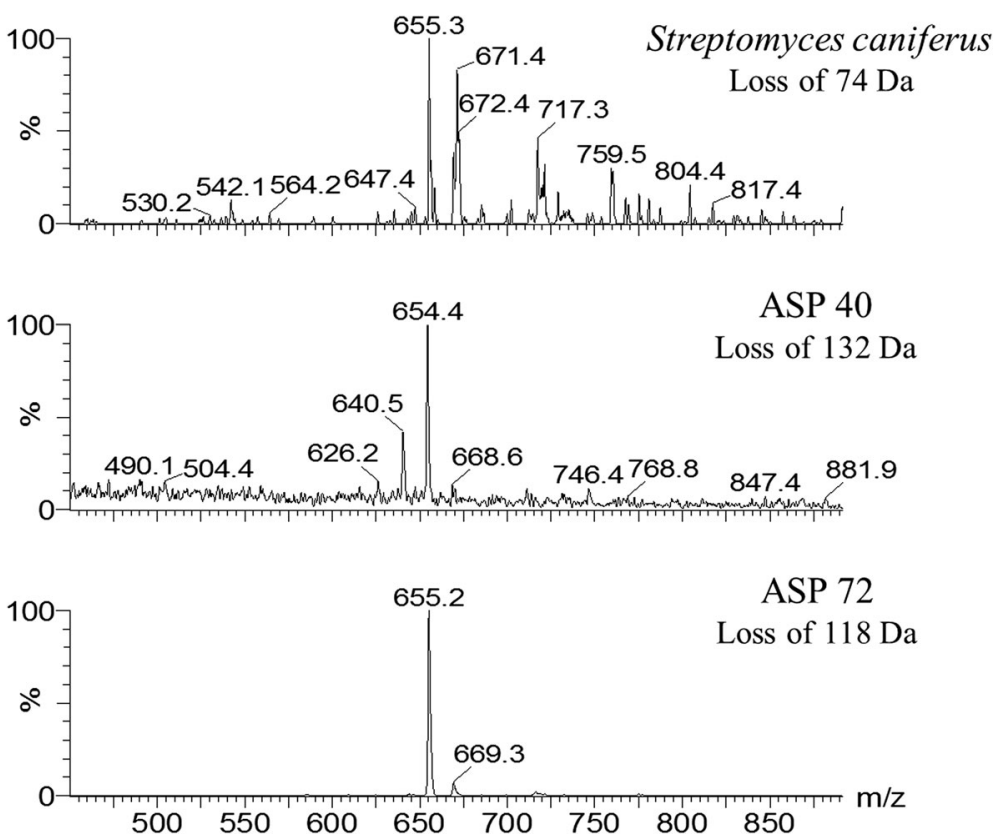

Fig. 4 Spectra of neutral-loss experiments for Streptomyces caniferus, Streptomyces aureus and Streptomyces eurocidicus 
We also demonstrated the importance of tandem mass-spectrometry experiments for the discovery of new compounds. Neutral-loss experiments allowed the identification of porphyrin II $(\mathrm{m} / \mathrm{z} 671)$ in a crude extract, which had not been identified in fractions enriched with porphyrins.

Isolate IIL-Ac-ASP18v produces porphyrins with high structural diversity and hydrophobicity. Porphyrin $I I$ is highly hydrophilic $(\log P 4.16)$, while porphyrin $I(\log P$ 5.64) shows a similar hydrophobicity to coproporhyrin $I$ $(\log P$ 5.22). The phototoxicity of porphyrins seems to depend on their structure, as their phototoxic activity increases with their hydrophobicity [47]. Therefore, the use of these compounds in photodynamic therapy must rely on the capacity of photosensitizers to move across the cell membrane, which will depend on their hydrophobicity. Molecules with $\log P$ values between 8 and 10 are considered moderately or highly hydrophobic, and are likely to be the most toxic as they can diffuse through cell membranes, move into the cell and become integrated into subcellular membranes such as the mitochondrial and lysosomal membranes, Golgi apparatus and rough endoplasmic reticulum. However, even lesshydrophobic compounds can actively or passively diffuse through the cell membrane if electrically charged, due to ionic interactions with groups at the cell surface. Cationic compounds are often located in mitochondria, while anionic compounds are accumulated at the lysosomal level [39].

Ben-Dror et al. [48] employed a series of synthetic porphyrins ( $\log P$ between 7.4 and 10.5 , as estimated with the ChemDraw software) with peripheral modifications that were expected to change the hydrophobicity with no change to the chromophore group. They measured the binding constant to liposomes, and determined that in highly hydrophobic porphyrins, neither the lipophilicity nor the passive binding to liposomes adequately predicted the cell uptake. In these cases, $\log P$ is not the only factor that should be used to predict porphyrin activity, and should be evaluated with caution as this may produce misleading conclusions, as in the case of passive uptake into liposomes, or be irrelevant in cases where other uptake mechanisms predominate, as with cells and highly apolar molecules. The singlet-oxygen production showed no significant changes.

Photosensitizers such as porphyrins generally lack cytotoxicity in the absence of light, which could be an advantage in biological systems where rapid breakdown of the photosensitizer after use is necessary. However, for industrial applications this is an undesirable aspect [44].

Similarly to other photosensitizers (e.g. xanthenes), porphyrins have been reported to affect the epithelial membrane of the midgut of insects and to inhibit insect feeding [39]. Amor et al. [41] discussed the efficiency of hematoporphyrin against Ceratitis capitata (Mediterranean fruit fly), Bactrocera (Dacus) oleae (olive fruit fly) and Stomoxys calcitrans (stable fly). Ceratitis capitata showed about $70 \%$ mortality after $1 \mathrm{~h}$ exposure to $11-$ $12 \mu \mathrm{mol} . \mathrm{mL}^{-1}$ (approximately $6.5 \mathrm{mg} \cdot \mathrm{mL}^{-1}$ ) of hematoporphyrin; while in our experiment, the active fraction of porphyrins produced by IIL-Ac-18 V showed an $\mathrm{LD}_{50}$ of $3.6 \mathrm{mg} \cdot \mathrm{mL}^{-1}\left(37.7 \mu \mathrm{g} \cdot \mathrm{cm}^{-2}\right)$. Bactrocera (D.) oleae showed lower photosensitivity than did $C$. capitata. Additional data on the efficacy of porphyrin mixtures for C. capitata control also indicated the importance of the porphyrin structure to their insecticidal activity. The amphiphilic cationic porphyrin DDP $(\log P 20)$ produced high mortality, while hematoporphyrin ( $\log P 12)$ was nearly atoxic [48]. However, high hydrophobicity can also lead to porphyrin aggregation, which would reduce its photoactivity [47]. These results reveal the importance of the porphyrin structure, and $\log P$ does not necessarily correlate directly with porphyrin biological activity.

Before field application can be recommended, important aspects of porphyrin-plant interactions must be considered based on experience with the use of tetrapyrroledependent photodynamic herbicides (TDPH). TDPH have been considered phytotoxic to certain plants, which are sprayed in the dark a few hours before they are exposed to light. Once exposed to light, the plants can accumulate massive amounts of tetrapyrroles, and damage appears after $20 \mathrm{~min}$, becoming irreversible after $60 \mathrm{~min}$. The toxicity of TDPH to plants is age- and species-dependent: dicotyledonous weeds such as mustard, red-root pigweed, common purslane and lamb's quarter are very susceptible, while monocotyledonous plants such as corn, wheat, barley and oats are not $[49,50]$. Therefore, the use of new phorphyrins as described here to control chewing insects such as the fall armyworm in field applications will require additional assays to check for plant toxicity and photodegradation that may occur once the molecules are exposed to light.

\section{Conclusions}

Our results demonstrated the importance of bacterial insect symbionts as sources of new and/or bioactive compounds. We used an unusual approach to pursue the isolation of bioactive molecules, by focusing on crude extracts with low insecticidal activity, aiming to identify bioactivity among the least-abundant molecules in the crude extract. The crude extracts from IIL-AcASP18v showed a complex chemical composition after analysis by direct insertion in the mass spectrometer, in positive mode (ESI+). After isolation of the porphyrin fraction, the insecticidal activity induced up to $100 \%$ larval mortality $\left(\mathrm{LD}_{50}=37.7 \mu \mathrm{g} \cdot \mathrm{cm}^{-2}\right)$, proving our strategy successful. The use of sensitive analytical tools such as 
mass spectrometry allowed the characterization of two new porphyrins.

\section{Methods \\ Microorganisms: Isolation and identification \\ Microorganisms were isolated from the leaf-cutting ant Acromyrmex coronatus (Hymenoptera, Formicidae) using ISP2 [51], ISP4 [51] and chitin [52] as culture media. The isolates obtained were identified based on 16S rRNA analysis (unpublished data). These isolates were then used to screen for insecticidal activity and porphyrin biosynthesis.}

\section{$16 \mathrm{~S}$ rRNA gene sequencing analysis}

A selected bacterial isolate (IIL-Ac-18dV) was grown at $28{ }^{\circ} \mathrm{C}$ for $24 \mathrm{~h}$ under constant agitation $(120 \mathrm{rpm})$ in $1 \mathrm{~mL}$ of the same culture medium used in the initial isolation. Cells were precipitated by centrifugation $(2000 g \times 5 \mathrm{~min})$ and then used for genomic DNA extraction [53]. DNA quality and integrity were assessed after electrophoresis in $0.8 \%(w / v)$ agarose gel containing $0.5 \mu \mathrm{g} / \mathrm{mL}$ ethidium bromide at $70 \mathrm{~V}$ for $1 \mathrm{~h}$ in TAE buffer (40 mM Tris-acetate, $1 \mathrm{mM}$ EDTA, pH 7.2), and spectrophotometry analysis using the A260/280 ratio $[54,55]$. DNA samples were subjected to PCR amplification of a fragment of the $16 \mathrm{~S}$ rRNA gene using 10-20 ng of genomic DNA and the universal primer set $8 \mathrm{f}\left(5^{\prime}\right.$-AGA GTT TGA TCC TGG CTC AG-3') and 1491r (5'-GGT TAC CTT GTT ACG ACT T-3') [56] in $1 \times$ enzyme buffer, $1.5 \mathrm{mM} \mathrm{MgCl}, 0.2 \mathrm{mM}$ dNTPs, $0.32 \mu \mathrm{M}$ of each primer, and $0.625 \mathrm{U}$ of Taq polymerase (Promega), in a final reaction volume of $25 \mu \mathrm{L}$. PCR cycling conditions were $4 \mathrm{~min}$ at $95{ }^{\circ} \mathrm{C}(1 \times)$; $95^{\circ} \mathrm{C}$ for $1 \mathrm{~min}, 55^{\circ}$ $\mathrm{C}$ for $1 \mathrm{~min}$, and $72{ }^{\circ} \mathrm{C}$ for $2 \mathrm{~min}(35 \times)$, followed by a final extension at $72{ }^{\circ} \mathrm{C}$ for $10 \mathrm{~min}(1 \times)$. The $16 \mathrm{~S}$ rRNA fragment obtained was submitted to bidirectional sequencing at the Laboratório de Biologia Molecular de Plantas, Departamento de Ciências Biológicas, ESALQ/USP, in an ABI 3730 DNA Analyzer using the BigDye ${ }^{\circ}$ Terminator v3.1 Cycle Sequencing kits. The sequence obtained was viewed and edited using Finch TV v1.4.0 (Geospiza Inc.) and forward and reverse reads were assembled in a single $\sim 1350$ bp-long read using the Blast2 tool. The 16S rDNA fragment obtained was used in heuristic blast searches against the nucleotide databases of the $\mathrm{Na}$ tional Center for Biotechnology Information (NCBI) (http://www.ncbi.nlm.nih.gov/) and EzTaxon [57] and (http://www.ezbiocloud.net/) for the tentative identification of the isolated bacterium. The sequence obtained for the isolate was deposited in GenBank under accession number KX762323.

\section{Crude extract preparation}

The selected isolate (IIL-Ac-18dV) and other microorganisms from our bank of isolates were inoculated in ISP2 medium and cultured for $7 \mathrm{~d}$ at $28{ }^{\circ} \mathrm{C}$ under constant shaking $(130 \mathrm{rpm})$. Crude extracts were obtained by liquid-liquid extraction with one volume of ethyl acetate (Synth), following standard procedures [58].

\section{Isolation of porphyrins for insecticidal bioassay}

Isolate IIL-Ac-18dV was inoculated in $4.5 \mathrm{~L}$ of ISP2 medium. After liquid-liquid extraction, $180 \mathrm{mg}$ of crude extract was produced. The crude extract was purified using a Sephadex ${ }^{\text {Tx }}$ LH-20 (particle size range: $27-163 \mu \mathrm{m}$; mean diameter: $103 \mu \mathrm{m}$; GE Healthcare, Sweden) - packed column $(300 \times 20 \mathrm{~mm})$, with methanol (J.T. Baker) as the eluent. A total of 29 fractions, including an initial fraction $(30 \mathrm{~mL})+27$ fractions $(12 \mathrm{~mL}$ per fraction $)+$ a final fraction $(50 \mathrm{~mL})$, were collected. Eluted compounds were monitored for color and UV absorbance $(\lambda=254$ and $356 \mathrm{~nm}$ ). Pink fractions indicative of porphyrins were separated and analyzed by MS/MS experiments and subjected to biological assays.

\section{Chromatographic conditions for porphyrin purification}

Chromatographic analyses were performed in an Ultra High-Performance Liquid Chromatography system (UHPLC Accela 600, Thermo Scientific) equipped with a diode array detector, auto sampler and an ACE 5 column $(250 \times 4.6 \mathrm{~mm} ; 5 \mu \mathrm{m})$. Porphyrin was monitored at $\lambda=400,533$ and $575 \mathrm{~nm}$. Samples were eluted using a gradient of $0.1 \%$ formic acid (phase A) and methanol/ $0.1 \%$ formic acid (phase B). The gradient started with $90 \%$ phase B and increased linearly to $95 \%$ within $3 \mathrm{~min}$, with an additional hold for $7 \mathrm{~min}$ in $95 \%$ phase B. The flow rate was $1 \mathrm{~mL} \cdot \mathrm{min}^{-1}$. Peaks were purified using an ACE 5 column $(250 \times 7.75 \mathrm{~mm}, 5 \mu \mathrm{m})$ under the same elution gradient at a flow rate of $2.8 \mathrm{~mL} \cdot \mathrm{min}^{-1}$.

\section{Bioassay \\ Screening}

The insecticidal activity of isolate IIL-Ac- $18 \mathrm{dV}$ was evaluated against first instars of the fall armyworm Spodoptera frugiperda (Lepidoptera, Noctuidae) by exposing the larvae to a surface-treated artificial diet. The artificial diet used was that of Kasten et al. [59], and insect rearing and handling followed Parra [60]. Bioassays were conducted in sterile 24-well plates filled with $1.25 \mathrm{~mL}$ of artificial diet. After the diet solidified, $20 \mu \mathrm{L}$ of the test solution was applied to the diet surface. In the initial screenings of crude extracts, samples were diluted in methanol to $25 \mu \mathrm{g} . \mu \mathrm{L}^{-1}$, resulting in the application of $500 \mu \mathrm{g}$ of crude extract in each cell $\left(260 \mu \mathrm{g} . \mathrm{cm}^{-2}\right)$. Methanol was used as the negative control. After the solvent dried completely, each cell was inoculated with 
ten (10) 24 h-old larvae, totaling 240 larvae/treatment. Plates were maintained under controlled conditions (25 $\pm 2{ }^{\circ} \mathrm{C} ; 60 \pm 10 \% \mathrm{RH} ; 14 \mathrm{~h}$ photophase), and larval development and mortality were evaluated daily for $3 \mathrm{~d}$. Mortality was assessed by touching the last abdominal segments, and larvae that were unresponsive or showed uncoordinated movements were considered dead.

\section{Porphyrin bioassay}

Insecticidal activity of the purified porphyrin fraction produced by isolate IIL-Ac- $18 \mathrm{dV}$ was evaluated using third instars of $S$. frugiperda, at 1, 2, 8, 16, and $65 \mu \mathrm{g} . \mathrm{cm}$ -2 . Bioassays were performed as above, but only three third instars were placed in each well of the plates, totaling 72 larvae/treatment. Plates were maintained under the same conditions, and larval development and mortality assessed as above. The program PoloPlus 1.0 was used to determine the dose-response curve and $\mathrm{LD}_{50}$ concentration, by Probit analysis (Leora Software, 1987).

The two major porphyrins (coproporphyrin and porphyrin $I I)$ in the porphyrin fraction were isolated and individually tested for insecticidal activity against third instars of $S$. frugiperda at the estimated $\mathrm{LD}_{50}$ concentration for the whole porphyrin fraction, as described above.

\section{MS and MS/MS experiments}

The crude extract and porphyrin-enriched fractions were analyzed by direct insertion in a $\mathrm{Xevo}^{\text {тм }}$ TQ-S (Waters Corporation) mass spectrometer coupled with Acquity ${ }^{\text {тм }}$ Ultra High-Performance Liquid Chromatography (UPLC ${ }^{\mathrm{rм}}$, Waters). The mass spectrometer operated with electrospray ionization in the positive mode (ESI+). The flow rate was $0.15 \mathrm{~mL} \cdot \mathrm{min}^{-1}$. The capillary voltage and the spray voltage were set to $3.3 \mathrm{kV}$ and $60 \mathrm{~V}$, respectively; the desolvation temperature was $350{ }^{\circ} \mathrm{C}$; and argon was used as the collision gas.

\section{Porphyrin characterization}

Fractions obtained from the crude extract were analyzed by direct insertion in a mass spectrometer operating in positive (ESI+) and negative (ESI-) modes, in a full scan experiment, and fractions with similar chemical compositions were pooled. The porphyrins present in the active fraction were characterized with collision-induced dissociation (CID) experiments employing coproporphyrin I, due to the availability of the fragmentation profile in the literature $[45,46]$. Several collision energies were tested $(20-70 \mathrm{~V})$ before $50 \mathrm{~V}$ was selected as the collision energy. The concentration of the porphyrin fractions was $5 \mu \mathrm{g} . \mathrm{mL}^{-1}$ in methanol. The hydrophobicity of the porphyrins identified was also estimated, by determining the partition coefficient between an organic solvent and water, or $\log P$, a measurement normally used to predict the ability of a molecule to diffuse into biomembranes. Theoretical values of $\log P$ for the porphyrins produced by isolate IIL-Ac-ASP18v were calculated using the commercial software Chem DrawPro 8.0 (CambridgeSoft Corporation).

\section{Neutral-loss experiment}

Neutral-loss experiments were performed in order to search for porphyrins in crude extracts from 67 antectosymbiont isolates (crude extract preparations were obtained as described above). Selected neutral losses were $60 \mathrm{Da}, 74 \mathrm{Da}, 118 \mathrm{Da}$ and $132 \mathrm{Da}$. These neutral losses were selected based on the main fragments found in CID experiments for coproporphyrin I, the major porphyrin present in the active fraction of isolate IIL-Ac-18dV and previously described $[45,46]$, which allowed the dereplication studies for this compound. The collision energy employed was $50 \mathrm{~V}$. The concentration of the crude extracts was $5 \mu \mathrm{g} \cdot \mathrm{mL}^{-1}$ in methanol. Ions that showed two losses were analyzed by daughter scan experiments to obtain structural information.

\section{LC-MS conditions}

The analyses of isomers of porphyrins and of the crude extracts obtained under acidic conditions were conducted on a LC-MS in a Xevo TQ-S (Waters Corporation) Mass Spectrometer coupled with Acquity Ultra HighPerformance Liquid Chromatography (UPLC, Waters). Samples were eluted using a gradient of $0.1 \%$ formic acid (phase A) and methanol/0.1\% formic acid (phase B). The gradient started with $40 \%$ phase B and increased linearly to $95 \%$ within $5 \mathrm{~min}$, with an additional hold for $2 \mathrm{~min}$ in $95 \%$ phase $B$. The flow rate was $0.4 \mathrm{~mL} \cdot \mathrm{min}^{-1}$. The mass spectrometer operated with electrospray ionization in the positive mode $(\mathrm{ESI}+)$. The capillary voltage and spray voltage were set at $3.0 \mathrm{kV}$ and $40 \mathrm{~V}$, respectively; with desolvation temperature $300{ }^{\circ} \mathrm{C}$, source temperature $120^{\circ}$ $\mathrm{C}$, argon used as the collision gas, and collision gas flow $0.2 \mathrm{~mL} \cdot \mathrm{min}^{-1}$.

\section{Abbreviations}

CID: Collision-induced dissociation; Da: Daltons; DPP: diketopyrrolopyrrole; LD: lethal dose; MS: mass spectrometry; PS: photosensitizer; ROS: reactive oxygen species; rRNA: ribosomal ribonucleic acid; UV: ultraviolet

\section{Acknowledgments}

We thank the Fundação de Amparo à Pesquisa do Estado de São Paulo (FAPESP) for providing a fellowship to AFCM (Process 2014/21584-3) and a research grant to FLC (Process 2011/50877-0).

\section{Funding}

We thank the Fundação de Amparo à Pesquisa do Estado de São Paulo (FAPESP) for providing a fellowship to AFCM (Process 2014/21584-3) and a research grant to FLC (Process 2011/50877-0).

Availability of data and materials

All data analyzed during this study are included in this published article. The datasets analyzed during the current study are available from the

corresponding author AFCM on reasonable request. 


\section{Authors' contributions}

FLC and AFCM designed the experiments. AFCM analyzed and interpreted all mass spectra. LGA performed the bioassays. AFCM and LABM elucidated the molecular structures. AFCM wrote and FLC edited the initial draft of the manuscript. All authors read and approved the final version of the manuscript.

\section{Ethics approval and consent to participate}

Not applicable.

\section{Consent for publication}

Not applicable.

\section{Competing interests}

The authors declare that they have no competing interests.

\section{Publisher's Note}

Springer Nature remains neutral with regard to jurisdictional claims in published maps and institutional affiliations.

\section{Author details}

'Laboratório de Interações em Insetos, Departamento de Entomologia e Acarologia, Escola Superior de Agricultura "Luiz de Queiroz", Universidade de São Paulo, Av Pádua Dias 11, 13418-900, Piracicaba, SP, Brazil. Laboratório de Espectrometria de Massas Aplicada a Produtos Naturais, Departamento de Química, Faculdade de Filosofia, Ciências e Letras de Ribeirão Preto, Universidade de São Paulo, Av Bandeirantes 3900, 14040-901, Ribeirão Preto, SP, Brazil.

\section{Received: 6 December 2016 Accepted: 20 June 2017}

\section{Published online: 27 June 2017}

\section{References}

1. Catarino R, Ceddia G, Areal FJ, Park J. The impact of secondary pests on Bacillus thuringiensis (Bt) crops. Plant Biotechnol J. 2015;13(5):601-12.

2. Popp J, Petö K, Nagy N. Pesticide productivity and food security. Agron Sustain Dev. 2013;33(1):243-55.

3. Barrows G, Sexton S, Zilberman D. Agricultural biotechnology: the promise and prospects of genetically modified crops. J Econ Perspect. 2014;28(1):99-120.

4. Gerwick BC, Sparks TC. Natural products for pest control: an analysis of their role, value and future. Pest Manag Sci. 2014;70(8):1169-85.

5. Lefebvre M, Langrell SRH, Gomez-y-Paloma S. Incentives and policies for integrated pest management in Europe: a review. Agron Sustain Dev. 2015:35(1):27-45.

6. Sparks TC. Insecticide discovery: an evaluation and analysis. Pest Biochem Physiol. 2013;107(1):8-17.

7. Poulsen M, Oh DC, Clardy J, Currie CR. Chemical analyses of wasp-associated Streptomyces bacteria reveal a prolific potential for natural products discovery. PLoS One. 2011;6(2):e16763.

8. Oh DC, Poulsen M, Currie CR, Clardy J. Dentigerumycin: a bacterial mediator of an ant-fungus symbiosis. Nat Chem Biol. 2009;5:391-3.

9. Oh DC, Poulsen M, Currie CR, Clardy J. Sceliphrolactam, a polyene macrocyclic lactam from a wasp-associated Streptomyces sp. Org Lett. 2011;13(4):752-5.

10. Carr G, Poulsen M, Klassen JL, Hou Y, Wyche TP, Bugni TS, et al. Microtermolides a and B from termite-associated Streptomyces sp. and structural revision of vinylamycin. Org Lett. 2012;14(11):2822-5.

11. Crawford JM, Clardy J. Bacterial symbionts and natural products. Chem Commun. 2011:47(27):7559-66.

12. Brachmann $A O$, Bode $H B$. Identification and bioanalysis of natural products from insect symbionts and pathogens. Adv Biochem Eng Biotechnol. 2013;135:123-55

13. Douglas AE. Symbiotic microorganisms: untapped resources for insect pest control. Trends Biotechnol. 2013;25(8):338-42.

14. De Bary A. The phenomenon of symbiosis. Karl J. Trubner: Strasbourg 1879. 364 p.

15. Van Born S, Billen J, Boomsma JJ. The diversity of microorganisms associated with Acromyrmex leafcutter ants. BMC Evol Biol. 2002;2:9-20.

16. Zucchi TD, Guidolin AS, Cônsoli FL. Isolation and characterization of actinobacteria ectosymbionts from Acromyrmex subterraneus brunneus (hymenoptera, Formicidae). Microbiol Res. 2011;166(1):68-76.
17. Poulsen M, Bot ANM, Currie CR, Nielsen MG, Boomsma JJ. Within-colony transmission and the cost of a mutualistic bacterium in the leaf cutting ant Acromyrmex octospinosus. Funct Ecol. 2003;17(2):260-9.

18. Haeder S, Wirth R, Herz H, Spiteller D. Candicidin-producing Streptomyces support leaf-cutting ants to protect their fungus garden against the pathogenic fungus Escovopsis. Proc Natl Acad Sci U S A. 2009;106(12):4742-6.

19. Barke J, Seipke RF, Grüschow S, Heavens D, Drou N, Bibb M, et al. A mixed community of actinomycetes produce multiple antibiotics for the fungus farming ant Acromyrmex octospinosus. BMC Biol. 2010;8:109-19.

20. Seipke RF, Barke J, Brealey C, Hill L, Yu DW, Goss RJM, et al. A single Streptomyces symbiont makes multiple antifungals to support the fungus farming ant Acromyrmex octospinosus. PLoS One. 2011;6(8):e22028.

21. Schoenian I, Spiteller M, Ghaste M, Wirth R, Herz H, Spiteller D. Chemical basis of the synergism and antagonism in microbial communities in the nests of leaf-cutting ants. Proc Natl Acad Sci U S A. 2010;108(5):1955-60.

22. Cafaro MJ, Currie CR. Phylogenetic analysis of mutualistic filamentous bacteria associated with fungus-growing ants. Can J Microbiol. 2005:51:441-6.

23. Poulsen M, Cafaro M, Boosma JJ, Currie CR. Specificity of the mutualistic association between actinomycete bacteria and two sympatric species of Acromyrmex leaf-cutting ants. Mol Ecol. 2005;14(11):3597-604.

24. Kost C, Lakatos T, Böttcher I, Arendholz WR. Redenbach, Wirth R. Nonspecific association between filamentous bacteria and fungus-growing ants. Naturwissenschaften. 2007;94(10):821-8.

25. Mueller UG. Symbiont recruitment versus ant-symbiont co-evolution in the attine ant-microbe symbiosis. Curr Opinion Microbiol. 2012;15(3):269-77.

26. Sen R, Ishak HD, Estrada D, Dowd SE, Hong E, Mueller UG. Generalized antifungal activity and 454-screening of Pseudnocardia and Amycolatopsis bacteria in nests of fungus-growing ants. Proc Natl Acad Sci U S A. 2009; 106(42):17805-10.

27. Andersen SB, Hansen LH, Sapountzis P, Sorensen SJ, Boosma JJ. Specificity and stability of the Acromyrmex-Pseudonocardia symbiosis. Mol Ecol. 2013:22:4307-21.

28. Haeder S, Wirth R, Herz H, Spiteller D. Candicidin-producing Streptomyces support leaf-cutting ants to protect their fungus garden against the pathogenic fungus Escovopsis. Proc Natl Acad Sci U S A. 2009;106:4742-6.

29. Mattose TC, Moreira DDO, Samuels RI. Symbiotic bacteria on the cuticle of the leaf-cutting ant Acromyrmex subterraneus protect workers from attack by entomopathogenic fungi. Biol Lett. 2012:8(3):461-4.

30. Klassen JL. Microbial secondary metabolites and their impacts on insect symbiosis. Curr Opin Insect Sci. 2014:4:15-22.

31. Mueller UG, Dash D, Rabeling C, Rodrigues A. Coevolution between Attine ants and actinomycete bacteria: a reevaluation. Evolution. 2008;62(11):2894-912.

32. Hooft JJJ, de Vos RCH, Ridder L, Vervoort J, Bino RJ. Structural elucidation of low abundant metabolites in complex sample matrices. Metabolomics. 2013:9(5):1009-18.

33. Ferreira DP, Conceição DS, Calhelha RC, Sousa T, Socoteanu R, Ferreira ICFR, et al. Porphyrin dye into biopolymeric chitosan films for localized photodynamic therapy of cancer. Carbohydr Polym. 2016;151(20):160-71.

34. Boscencu R, Oliveira AS, Ferreira DP, Ferreira LFV. Synthesis and spectral evaluation of some unsymmetrical mesoporphyrinic complexes. Int J Mol Sci. 2012;13:8112-25.

35. O'Connor AE, Gallagher WM, Byrne AT. Porphyrin and nonporphyrin photosensitizers in oncology: preclinical and clinical advances in photodynamic therapy. J Photochem Photobiol. 2009;85(5):1053-74.

36. Malikt Z, Hanania J, Nitzan Y. Bactericidal effects of photoactivated porphyrins - an alternative approach to antimicrobial drugs. J Photochem Photobiol B. 1990;5(3-4):281-93.

37. Vatansever F, de Melo WCMA, Avci P, Vecchio D, Sadasivam M, Gupta A, et al. Antimicrobial strategies centered around reactive oxygen species bactericidal antibiotics, photodynamic therapy, and beyond. FEMS Microbiol Rev. 2013;37(6):955-89.

38. Alves E, Faustino MAF, Neves MGPMS, Cunha A, Nadais $H$, Almeida A. Potential applications of porphyrins in photodynamic inactivation beyond the medical scope. J Photochem Photobiol C Photochem Rev. 2015:22·34-57.

39. Amor TB, Jori G. Sunlight-activated insecticides: historical background and mechanisms of phototoxic activity. Insect Biochem Molec Biol. 2000;30:915-25.

40. Buda V, Luksiene Z, Radziute S, Kurilcil N, Jursenas S. Search of photoinsecticides: effect of hematoporphyrin dimethyl ether on leaf mining pest Liriomyza bryoniae (Diptera: Agromyzidae). Agron Res. 2006;4:141-6.

41. Amor TB, Tronchin M, Bortolotto L, Verdiglione R, Joril G. Porphyrins and related compounds as photoactivatable insecticides 1 . Phototoxic activity of 
hematoporphyrin toward Ceratitis capitata and Bactrocera oleae. Photochem Photobiol. 1998;67(2):206-11.

42. Amor TB, Bortolotto L, Jori G. Porphyrins and related compounds as photoactivatable insecticides 2. Phototoxic activity meso-substituted porphyrins. Photochem Photobiol. 1998;68(3):314-8.

43. Silva EFF, Serpa C, Dabrowski JM, Monteiro CJP, Formosinho SJ, Stochel G, et al. Mechanisms of singlet-oxygen and superoxide-ion generation by porphyrins and bacteriochlorins and their implications in photodynamic therapy. Chem Eur J. 2010;16(30):9273-86.

44. De-Rosa MC, Crutchley JR. Photosensitized singlet oxygen and its applications. Coord Chem Rev. 2002;233-234(1):351-71.

45. Danton M, Lim CK. Porphyrin profiles in blood, urine and faeces by HPLC/ electrospray ionization tandem mass spectrometry. Biomed Chromatogr. 2006;20(6-7):612-21.

46. Bu W, Myers N, McCarty JD, O'Neill T, Hollar S, Stetson PL, et al. Simultaneous determination of six urinary porphyrins using liquid chromatography-tandem mass spectrometry. J Chromatogr B. 2003;783(2):411-23.

47. Jones $L R$, Grossweiner LI. Singlet oxygen generation by Photofrin ${ }^{\oplus}$ in homogeneous and light-scattering media. J Photochem Photobiol B. 1994;26(3):249-56.

48. Ben-Dror S, Bronshtein I, Wiehe A, Roder B, Senge MO, Ehrenberg B. On the correlation between hydrophobicity, liposome binding and cellular uptake of porphyrin sensitizers. Photochem Photobiol. 2006;82:695-701.

49. Rebeiz CA, Montazer-Zouhoor A, Hopen HJ, Wu SM. Photodynamic herbicides: 1. Concept and phenomenology Enzyme Microb Technol. 1984;6(9):390-6

50. Rebeiz CA, Reddy KN, Nandihalli UB, Velu J. Tetrapyrrole dependent photodynamic herbicides. Photochem Photobiol. 1990;52(6):1099-117.

51. Shirling EB, Gottlieb D. Methods for characterizations of Streptomyces species. Int J Syst Evol Microbiol. 1966;16:313-40.

52. Hsu SC, Lockwood JL. Powdered chitin agar as a selective medium for enumeration of actinomycetes in water and soil. J Appl Microbiol. 1975; 29(3):422-6.

53. Sunnucks $P$, Hales DF. Numerous transposed sequences of mitochondrial cytochrome oxidase I-II in aphids of the genus Sitobion (Hemiptera: Aphididae). Mol Biol Evol. 1996;13(3):510-24.

54. Gallagher SR, Desjardins PR. Quantitation of DNA and RNA with absorption and fluorescence spectroscopy. Curr Protoc Protein Sci. 2007;A-3D doi:10. $1002 / 0471140864$

55. Sambrook J, Russel DW. Molecular cloning: a laboratory manual 3rd Ed. New York: Cold Spring Harbor Laboratory Press; 2001.

56. Weisburg WG, Barns SM, Pelletier DA, Lane DJ. 165 ribosomal DNA amplification for phylogenetic study. J Bacteriol. 1991;173(2):697-703.

57. Kim OS, Cho YJ, Lee K, Yoon SH, Kim M, Na H, et al. Introducing EzTaxon-e: a prokaryotic 16S rRNA Gene sequence database with phylotypes that represent uncultured species. Int J Syst Evol Microbiol. 2012;62:716-21.

58. Melo IS, Sanhueza RMV. Métodos de seleção de microrganismos antagônicos a fitopatógenos: manual técnico. Embrapa-CNPMA: Jaguariúna; 1995.

59. Kasten P, Precetti AA, Precetti CM, Parra JRP. Dados biológicos comparativos de Spodoptera frugiperda (J.E. Smith, 1797) em duas dietas artificias e substrato natural. Rev Agric. 1978;53:68-78.

60. Parra JRP. Criação de insetos para estudo com patógenos. In: Alevs SB editor. Controle microbiano de insetos. Piracicaba: FEALQ; 1986. p. 348-73.

\section{Submit your next manuscript to BioMed Central and we will help you at every step:}

- We accept pre-submission inquiries

- Our selector tool helps you to find the most relevant journal

- We provide round the clock customer support

- Convenient online submission

- Thorough peer review

- Inclusion in PubMed and all major indexing services

- Maximum visibility for your research

Submit your manuscript at www.biomedcentral.com/submit

CBiomed Central 